\title{
The origin of midlatitude ice clouds and the resulting influence on their microphysical properties
}

\author{
Anna E. Luebke ${ }^{1}$, Armin Afchine ${ }^{1}$, Anja Costa ${ }^{1}$, Jens-Uwe Grooß $^{1}$, Jessica Meyer ${ }^{1, a}$, Christian Rolf ${ }^{1}$, Nicole Spelten ${ }^{1}$, \\ Linnea M. Avallone ${ }^{2, b}$, Darrel Baumgardner ${ }^{3}$, and Martina Krämer ${ }^{1}$ \\ ${ }^{1}$ Forschungszentrum Jülich, Institut für Energie und Klimaforschung (IEK-7), Jülich, Germany \\ ${ }^{2}$ National Science Foundation, Arlington, Virginia, USA \\ ${ }^{3}$ Droplet Measurement Technologies, Boulder, Colorado, USA \\ anow at: Bundesanstalt für Arbeitsschutz und Arbeitsmedizin, Unit "Exposure Scenarios", Dortmund, Germany \\ b formerly at: University of Colorado, Boulder, Colorado, USA \\ Correspondence to: Anna E. Luebke (a.luebke@fz-juelich.de)
}

Received: 24 November 2015 - Published in Atmos. Chem. Phys. Discuss.: 7 December 2015

Revised: 4 April 2016 - Accepted: 17 April 2016 - Published: 12 May 2016

\begin{abstract}
The radiative role of ice clouds in the atmosphere is known to be important, but uncertainties remain concerning the magnitude and net effects. However, through measurements of the microphysical properties of cirrus clouds, we can better characterize them, which can ultimately allow for their radiative properties to be more accurately ascertained. Recently, two types of cirrus clouds differing by formation mechanism and microphysical properties have been classified - in situ and liquid origin cirrus. In this study, we present observational evidence to show that two distinct types of cirrus do exist. Airborne, in situ measurements of cloud ice water content (IWC), ice crystal concentration $\left(N_{\text {ice }}\right)$, and ice crystal size from the 2014 ML-CIRRUS campaign provide cloud samples that have been divided according to their origin type. The key features that set liquid origin cirrus apart from the in situ origin cirrus are higher frequencies of high IWC ( $>100 \mathrm{ppmv}$ ), higher $N_{\text {ice }}$ values, and larger ice crystals. A vertical distribution of $N_{\text {ice }}$ shows that the in situ origin cirrus clouds exhibit a median value of around $0.1 \mathrm{~cm}^{-3}$, while the liquid origin concentrations are slightly, but notably higher. The median sizes of the crystals contributing the most mass are less than $200 \mu \mathrm{m}$ for in situ origin cirrus, with some of the largest crystals reaching $550 \mu \mathrm{m}$ in size. The liquid origin cirrus, on the other hand, were observed to have median diameters greater than $200 \mu \mathrm{m}$, and crystals that were up to $750 \mu \mathrm{m}$. An examination of these characteristics in relation to each other and their relationship to temperature provides strong evidence that these
\end{abstract}

differences arise from the dynamics and conditions in which the ice crystals formed. Additionally, the existence of these two groups in cirrus cloud populations may explain why a bimodal distribution in the IWC-temperature relationship has been observed. We hypothesize that the low IWC mode is the result of in situ origin cirrus and the high IWC mode is the result of liquid origin cirrus.

\section{Introduction}

Though difficulties and uncertainties associated with measuring and parameterizing cirrus cloud properties and the complex processes involved exist, the fact that cirrus clouds are a key component in the Earth's radiative budget is well established. Numerous studies have demonstrated the intricate details involved in putting together a complete and accurate portrayal of the radiative properties of cirrus clouds. For example, analyses have reported on the sensitivity to ice crystal sizes, shapes, and concentrations, cloud top height, optical depth, etc. and how these factors change within and between regions of the globe, (e.g., Stephens et al., 1990; Jensen et al., 1994; Heymsfield and McFarquhar, 1996; Zhang et al., 1999). Furthermore, recent studies, such as that from Joos et al. (2014), and references therein, highlight the intricacies of representing cirrus clouds accurately in simulations and reveal that this issue leads to questions in regard to the radiative role of cirrus clouds in the present and future climate. 
In situ observations and subsequent analyses of cirrus microphysical properties such as ice water content (IWC), ice crystal concentration $\left(N_{\text {ice }}\right)$, and ice crystal size contribute to the construction of a more accurate characterization of cirrus clouds by providing values that are the basis for creating and validating parameterizations developed for general circulation models (GCMs). These three properties are found to vary naturally over several orders of magnitude (Luebke et al., 2013; Schiller et al., 2008; Krämer et al., 2009; Lawson et al., 2010; Heymsfield et al., 2013); therefore it is more reasonable and useful to explore them in the context of their relationship to other environmental variables (e.g., temperature). This in turn allows us to infer other information such as the mechanism of ice crystal formation and growth and go on to develop classifications of cirrus clouds based on these relationships.

An analysis of a large database of cirrus data from Luebke et al. (2013) showed that there is a bimodal frequency distribution of IWC as a function of temperature. They hypothesized that the two modes are representative of the two formation pathways of cirrus ice crystals, homogeneous and heterogeneous ice nucleation. Both modes are observed over the complete cirrus temperature range, and the peak values of the modes increase with temperature. Furthermore, the low and high IWC modes correspond to respective $N_{\text {ice }}$. While that study points to differences in nucleation pathways as being the key to understanding these bi-modalities, studies like Muhlbauer et al. (2014) suggest that differences in larger scale dynamics are the important factor. Their study reported that two populations of ice crystals were observed in particle size distributions (PSDs) from the Small Particles in Cirrus (SPARTICUS) campaign. They found a narrow smallparticle mode and a broader large-particle mode (separated by a level area in the distribution, usually between about 40 and $100 \mu \mathrm{m})$. However, this bimodality was not consistently evident. Further, they found that subtropical and anvil cirrus types were more likely to display a bimodal PSD, while ridge-crest and frontal cirrus PSDs were more typically monomodal. An analysis of other microphysical properties also demonstrated strong ties to the large-scale dynamics of the environment in which they were observed.

A scan of the literature surrounding cirrus clouds shows that classification schemes based on large-scale dynamics or meteorology are commonly used, (e.g., Sassen, 2002; Heymsfield et al., 2002; Lynch et al., 2002; Muhlbauer et al., 2014; Jackson et al., 2015). Typically, the cirrus clouds are classified as "synoptic" or "convective", or they are classified based on more specific meteorology. However, Krämer et al. (2016) has recently proposed new definitions for a cirrus classification scheme based on the origin of the ice crystals - in situ and liquid origin cirrus clouds. The details of this scheme are further discussed in Sect. 2.

Briefly, in Krämer et al. (2016), various cirrus production and development scenarios are discussed. These scenarios are explored through extensive and detailed modeling work from a microphysics box model, MAID (Model for Aerosol and Ice Dynamics), and compared to in situ observations from several airborne campaigns. However, the frequently observed high IWC values in combination with high $N_{\text {ice }}$ are not represented in the model simulations, thus indicating that "classic" cirrus microphysics does not lead to such conditions. One feature that is not included in the MAID model is the possibility for preexisting ice. Preexisting ice means that the ice crystals are formed in the mixed-phase regime at warmer temperatures $(T>235 \mathrm{~K})$, but are eventually incorporated into a cirrus cloud where they contribute to the overall microphysics. This pathway could lead to a cirrus cloud that contains many large ice crystals and thus the high IWC values, particularly if the crystals first developed in an environment that allows them to grow larger.

The analysis presented here follows from Krämer et al. (2016) by using observational evidence to further explore and explain the two distinct types of cirrus proposed - in situ and liquid origin cirrus clouds. Krämer et al. (2016) used model results and a more broad campaign-case method to introduce this concept. The following study seeks to demonstrate the existence of these two cirrus cloud types by delving more deeply into how the microphysical properties differ from one type to the other. Specifically, we focus on IWC, $N_{\text {ice }}$, and ice crystal size. This is especially important for fully understanding cirrus clouds and how they should be properly represented in modeling scenarios as changes in microphysical properties will affect the radiative properties of cirrus clouds, both locally and globally.

\section{Cirrus cloud origins}

Cirrus analyses often categorize naturally occurring, nonaviation-induced cirrus clouds into two groups based on the meteorology associated with their development. However, the recent study from Krämer et al. (2016) introduced an updated classification of these two types, which instead refers to their origin - in situ and liquid. This classification is based on (i) the formation mechanism of the cloud particles (directly as ice or frozen liquid droplets), and is therefore tied to a temperature threshold of $-38^{\circ} \mathrm{C}$, below which liquid water drops do not exist, and, (ii) the vertical velocity, which determines the thickness of the cirrus. By default, a meteorological classification is also embedded within this scheme, but with some modification. This is discussed at the end of this section.

Cirrus clouds whose ice crystals have formed and grown within an ice cloud only environment are referred to as in situ origin cirrus clouds. These clouds form via heterogeneous and homogeneous ice nucleation whereby an air parcel rises and cools to a point at which a freezing threshold (i.e., the supersaturation with respect to ice needed to initiate nucleation) is crossed, and ice crystals can form and continue to grow as conditions allow. The freezing threshold is 

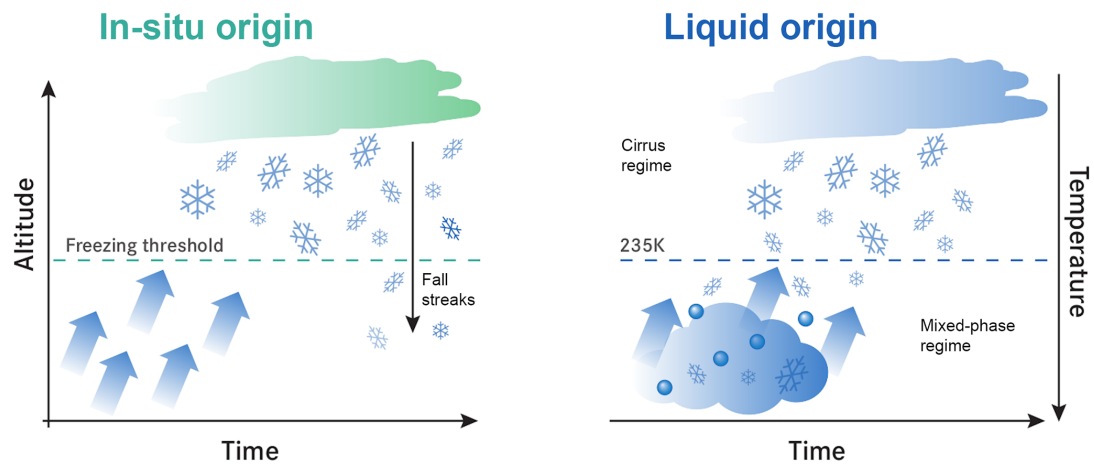

Figure 1. Schematic of the basic mechanism surrounding in situ origin cirrus (left) and liquid origin cirrus (right). Each scenario illustrates the movement of air and/or cloud particles from their origin to a cirrus cloud. Left panel (in situ origin): the "freezing threshold" indicates where heterogeneous and/or homogeneous ice nucleation takes place and cirrus development begins. Right panel (liquid origin): the cloud particles first form in the mixed-phase region of the atmosphere and become ice through heterogeneous or homogeneous drop freezing. After crossing the $235 \mathrm{~K}$ threshold, liquid water no longer exists, which indicates the boundary of the cirrus region of the atmosphere.

determined with respect to ice nuclei in the case of heterogeneous ice nucleation or with respect to supercooled solution particles in the case of homogeneous ice nucleation. Homogeneous ice nucleation refers to the process by which supercooled particles in solution freeze. This development process is illustrated simply in the schematic shown in Fig. 1, left. In situ origin cirrus clouds may also be observed in the form of fall streaks, i.e., where large ice crystals have sedimented to lower altitudes/higher temperatures. However, this phenomena was not observed in the data set used for this analysis.

Cirrus clouds whose ice crystals originally formed as liquid drops lower in the atmosphere $(T>235 \mathrm{~K})$, which subsequently froze while being lifted into the cirrus temperature region of the atmosphere, are referred to as liquid origin cirrus clouds (Fig. 1, right). This difference is important because liquid and mixed-phase clouds develop and are controlled by different microphysical processes, such as the mechanism described by the Köhler equation, than those found in ice-only atmospheric environments. These warmer clouds exist in a regime that supplies a greater amount of water vapor for cloud particle formation and growth. Furthermore, the population of effective cloud condensation nuclei $(\mathrm{CCN})$ can result in clouds with many liquid cloud particles. Heterogeneous drop freezing will be triggered in those particles containing an insoluble ice nucleus. Homogeneous drop freezing, which is something different from the homogeneous ice nucleation of aerosol particles in solution discussed in the previous paragraph, is also possible but will only occur at $-38^{\circ} \mathrm{C}$ if supercooled liquid water droplets still remain. These conditions also allow for other growth mechanisms, such as aggregation and riming, that are not always seen in the cirrus environment. Aggregation and riming can be important processes in liquid origin cirrus clouds, but mainly at higher vertical velocities (i.e., in strong convection). As shown in Fig. 1, we suggest that if the vertical motion is strong enough, any existing ice crystals or liquid droplets can also be lifted into the cirrus environment. Any ice crystals or frozen liquid drops observed within this space would then be identified as a cirrus cloud, regardless of their origin. Additionally, liquid origin cirrus clouds can be connected to in situ origin cirrus clouds. If the conditions allow for it (i.e., if the supersaturation reaches the homogeneous ice nucleation threshold), further ice nucleation events producing small ice crystals may take place in addition to the existing, large liquid origin cirrus crystals. The liquid origin cirrus type is where convective cirrus is classified. Warm conveyor belt cirrus and, in some cases, lee-wave-induced cirrus are also good candidates for inclusion in this category because they can involve a lifting of clouds to $T<-38^{\circ} \mathrm{C}$.

Though this classification is based on the ice crystal origin, it can also be compared to categorization based on meteorology. For example, as noted in the introduction, Muhlbauer et al. (2014) classify observations from the SPARTICUS campaign into groups such as ridge-crest, frontal, subtropical jet stream, and anvil cirrus. Krämer et al. (2016) explain that ridge-crest cirrus is comparable to in situ origin cirrus in a fast updraft case, while frontal, subtropical jet stream, and anvil cirrus fit into the liquid origin category and represent both slow and fast updraft cases. As discussed more thoroughly therein, this is further supported by observational similarities and differences between SPARTICUS and the campaigns (including ML-CIRRUS) used by Krämer et al. (2016) for their analysis.

\section{ML-CIRRUS 2014}

The primary data set used for this study comes from the recent ML-CIRRUS campaign, which took place in the spring of 2014. The campaign was based out of Oberpfaffenhofen, Germany using the HALO aircraft and comprises 16 flights in total covering various locations over the European continent (Voigt et al., 2016). Only 13 flights are used in the anal- 
ysis presented here. The remaining three flights have been excluded from our analysis because they were aimed at sampling pure contrail/aviation-induced cirrus or liquid clouds.

\subsection{Measurement of ice crystal properties: NIXE-CAPS particle spectrometer}

\subsubsection{Instrument description}

The instrument used in this study is a version of the Cloud Aerosol and Precipitation Spectrometer (CAPS) that was developed in 2001 to measure the properties of cloud and aerosol particles (Baumgardner et al., 2001). The CAPS is a combination probe that integrates two techniques for measuring the particle size distribution (PSD): the PSD of particles 0.6 to $50 \mu \mathrm{m}$ in diameter is measured with the Cloud and Aerosol Spectrometer (CAS) using light scattered from individual particles that pass through a focused laser beam. For measurements of particles 15-937 $\mu \mathrm{m}$ in diameter, the Cloud Imaging Probe (CIP), which utilizes the optical array probe (OAP) technique, is used. The new version of CAPS, operated by Forschungszentrum Jülich, is called NIXE-CAPS (Novel Ice Experiment-CAPS) and is described in more detail by Meyer (2012).

The improved features of the new instrument are briefly described here. Both the CAS and CIP are now equipped with the "particle-by-particle" option, meaning each particle is recorded with its own time stamp. This option makes a particle interarrival time analysis, and therefore the removal of most shattered ice crystal fragments, possible (Field et al., 2006). Additionally, the CIP has been upgraded to imaging at a higher resolution with three gray-scale levels (CIPGrayscale), which improves the discrimination of out of focus particles.

The CAS has undergone several modifications as well. Firstly, the inlet tube, which originally had a stepped, slight expansion, has been replaced by a completely straight tube to ensure that the velocity in the inlet equals the aircraft speed so that the particles are sampled nearly isokinetically. Secondly, the entry of the CAS inlet tube has been sharpened to a knife edge to minimize the area susceptible to shattering of ice particles. Lastly, a new detector was implemented that allows the separation of spherical from non-spherical (aspherical) shapes (CAS-DPOL). Briefly, it measures the intensity of the parallel and perpendicularly polarized components of the scattered light caused by single atmospheric particles (see Baumgardner et al., 2014, for more details).

In addition to the instrument improvements, a data processing library (NIXE-Lib) was developed for fast and precise simultaneous data analysis of the NIXE-CAPS measurements, which has been described in Meyer (2012). A flowchart of the NIXE-Lib is shown in Fig. 2, where all subsequent standard data processing procedures are displayed, including time synchronization of the measurements, velocity correction, corrections of particle counts, particle sizing $\left(D_{\mathrm{p}}\right.$ : optical equivalent diameter for CAS-DPOL, area equivalent diameter for CIP-Grayscale), interarrival time analysis, and finally, calculation of the particle concentrations ( $\mathrm{d} N$ : particle concentration per size bin, $N_{\text {tot }}$ : total ambient particle concentration; the true air speed (TAS) is used for the calculations), and the PSDs $\left(\mathrm{d} N / \mathrm{d} \log D_{\mathrm{p}}\right)$ for CASDPOL and CIP-Grayscale.

The sphericity classification is performed for the size range $3-50 \mu \mathrm{m}$ by using the polarization channel of the CASDPOL (to be discussed further in an upcoming analysis) and for sizes $70-240 \mu \mathrm{m}$ from CIP-Grayscale measurements using the habit identification algorithm of Korolev and Suss$\operatorname{man}(2000)$.

As a last step, the PSDs of CAS-DPOL and CIP-Grayscale are merged into a single PSD covering the range of 0.6 to $937 \mu \mathrm{m}$. Henceforth, the size bins up to $20 \mu \mathrm{m}$ are taken from the CAS-DPOL and those larger than $20 \mu \mathrm{m}$ from the CIPGrayscale. This threshold is used since the CIP-Grayscale has a larger sampling volume than the CAS-DPOL, thus providing better particle sampling statistics. Particles larger than $3 \mu \mathrm{m}$ in diameter are classified as cloud, while the smaller particles are considered aerosols. Thus, for this analysis, particles in the size range 3-937 $\mu \mathrm{m}$ are used. According to Meyer (2012), the uncertainties associated with the particle concentration for the NIXE-CAPS sum up to a total of $\pm 20 \%$. However, as noted by Jackson et al. (2015), though ice crystals of $D<60 \mu \mathrm{m}$ are a significant ice crystal population, they also contain the largest uncertainty in a given PSD. This also holds true for the data presented in this analysis.

\subsubsection{IWC from NIXE-CAPS measurements}

During ML-CIRRUS 2014, the IWC was derived from the PSD information from NIXE-CAPS by integrating the particle mass in each size bin. The mass-dimension relation that we used for the different sizes is based on Mitchell et al. (2010) since it was developed using a good agreement between aircraft measurements (during the Tropical Composition, Cloud and Climate Coupling mission, TC4). Namely, this IWC derivation comes from PSD measurements using another type of optical array probe, 2D-S (with interarrival time correction to remove shattered particles), and simultaneous measurements with a CVI (Counterflow Virtual Impactor). The Mitchell et al. (2010) relationship is

$m=a \cdot D^{b}$,

where $m$ is ice particle mass in $\mathrm{mg}$ and

$a=0.082740, \quad b=2.814$ for $\quad D<240 \mu \mathrm{m}$

$a=0.001902, \quad b=1.802$ for $D>240 \mu \mathrm{m}$.

As shown in Fig. 3, we modified the relationship for ice crystals with $D<240 \mu \mathrm{m}$ so that 


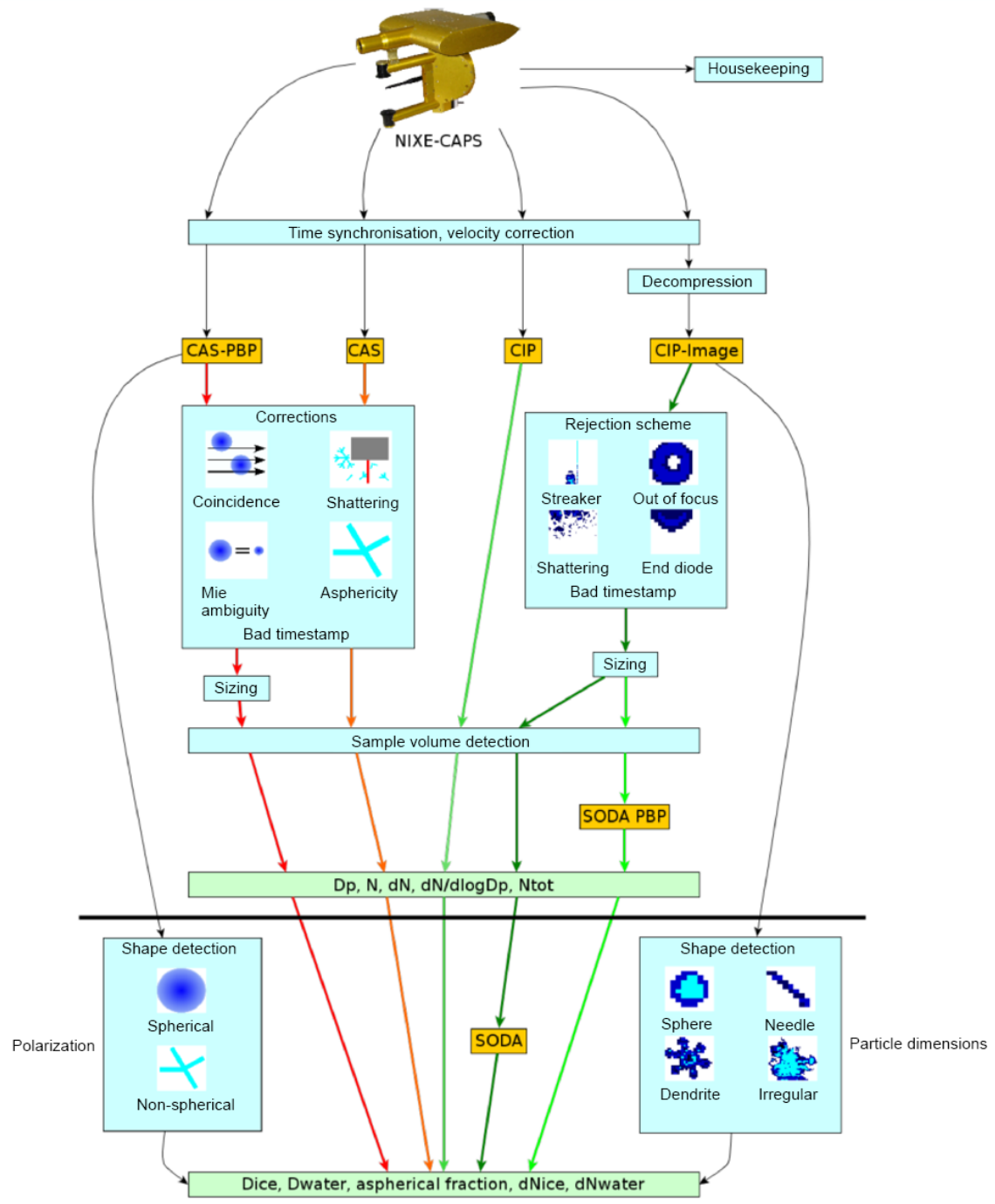

Figure 2. Flowchart of the NIXE-CAPS data processing library, NIXE-Lib. The data first undergoes time synchronization and velocity correction. It continues into various corrections of particle counts and sizing. The final steps produce a particle concentration for CAS-DPOL and CIP-Grayscale, respectively. SODA: a software program developed at the National Center for Atmospheric Research (NCAR) in Boulder, Colorado, USA. This program is embedded in the NIXE-Lib. See Meyer (2012) for more details.

for $D<10 \mu \mathrm{m}$

for $D=10-240 \mu \mathrm{m}$

for $D>240 \mu \mathrm{m}$

$a=0.058$,

$a=0.001902$,

This modification is derived from an inspection of the sphericity of the ice crystals (see previous section), which shows that there are many spherical ice particles present during the campaign, especially at the smaller sizes. Also, the confidence in using such a relationship has recently been discussed in the new, extensive analysis from Erfani and Mitchell (2016) where they provide observation based m-D relationships and demonstrate that the relationship is nearly independent of cirrus type.

\subsection{3 $\quad N_{\text {ice }}$ and $R_{\text {ice }}$ from NIXE-CAPS measurements}

$N_{\text {ice }}$ and mass mean radius $\left(R_{\text {ice }}\right)$ observations for this analysis also come from the NIXE-CAPS. $R_{\text {ice }}$ in $\mu \mathrm{m}$ is calculated with

$R_{\text {ice }}=1 e^{4} \cdot\left(\frac{1 \cdot e^{-6} \mathrm{IWC}}{N_{\text {ice }}} \cdot \frac{3}{4 \pi \rho}\right)^{1 / 3}$,

where IWC is in $\mathrm{mg} \mathrm{m}^{-3}, N_{\text {ice }}$ is in $\mathrm{cm}^{-3}$, and $\rho$ is $0.92 \mathrm{~g} \mathrm{~cm}^{-3}$. Note that $R_{\text {ice }}$ is only discussed in Sect. 4.2 and is used for consistency in a discussion that includes a figure taken directly from Krämer et al. (2016). Elsewhere in the paper, ice crystal sizes are referred to in diameter. 


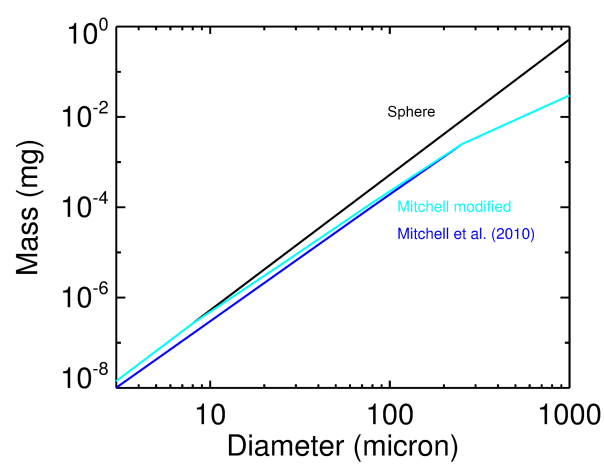

Figure 3. $m-D$ relationship for spheres (black) and cirrus cloud particles (blue), as in Mitchell et al. (2010), and the modified relationship for this analysis (turquoise).

\subsubsection{Modal mass diameter}

The primary ice crystal size variable used in this analysis is modal mass diameter $\left(D_{\text {ice, mode }}\right)$. This variable is calculated by considering the observed ice crystal size distribution for each time step. The mass in each size bin is calculated using the modified Mitchell et al. (2010) relationship discussed in Sect. 3.1.2. Then, the bin size where the maximum amount of mass is located is determined to be the modal mass size. It is worth considering this variable in addition to the traditionally used size variables, such as $R_{\text {ice }}$, because we are interested in visualizing large particles and determining whether those particles are in fact related to very high IWC values.

\subsection{Origin classification}

In order to categorize each ML-CIRRUS flight, or flight segment when appropriate, by origin type, information from the CLaMS-Ice model was used. A detailed description of the model, including a validation study and comparison between model and in situ data, will take place in an additional analysis, but is briefly discussed here. The Chemical Lagrangian Model of the Stratosphere (CLaMS; McKenna et al., 2002; Konopka et al., 2007) performs a back trajectory analysis using location information from the aircraft along the flight path (time, location) and ECMWF operational analysis data. The trajectories are performed over a time frame specified by the operator. Next, the CLaMS-Ice model is run in the forward direction and uses the two-moment box-model developed by Spichtinger and Gierens (2009a) to simulate cirrus cloud development. This modeling scheme only considers the trajectories that end at $T<238 \mathrm{~K}$. If a part of the trajectory existed at $T>238 \mathrm{~K}$ before crossing into the colder cirrus environment, then it is possible for the forward model to be initialized with preexisting ice from mixed-phase clouds, if present. Whether or not preexisting ice exists is determined by the IWC values found in the ECMWF data.

The resulting simulated clouds show a clear difference between the two origins. An example of each origin type is shown in Fig. 4. The flights from 7 and 11 April were chosen to represent in situ and liquid origin clouds, respectively. The figure illustrates the location of the aircraft in terms of the distance flown and pressure, and is marked with a solid black line to form a flight track. The simulated clouds are depicted in a curtain format using the IWC values calculated by CLaMS-Ice at each point along the flight track. Grey areas appear for $T>238 \mathrm{~K}$. The liquid origin cirrus clouds (top) are found at lower altitudes (higher pressures) and exhibit a very high IWC (on the order of $100 \mathrm{ppmv}$ ) consistently throughout the base of the cloud. They are easily identified by eye due to the bright orange colors. On the other hand, the in situ origin clouds (bottom) are found at higher altitudes. The simulations show a more cellular appearance to the cloud structure and IWC values that are lower than their liquid origin counterparts. These clouds are also observed on top or to the sides of the liquid origin cirrus, which is also illustrated by the 11 April flight in Fig. 4.

We were able to use this information along each of the flight tracks to determine whether the flight or individual flight segments represent in situ or liquid origin cirrus. Flights and flight segments were then divided accordingly. Temperature criteria were also applied to the classification. For the in situ origin cases, only cirrus sampled at $T<235 \mathrm{~K}$ are considered. Clouds warmer than this temperature are likely to be influenced by mixed-phase cloud microphysics. Thus, for the liquid origin cases, the temperature range is extended to capture that influence, and ice-only clouds at $T<250 \mathrm{~K}$ are considered. Clouds above that temperature threshold are likely to be mixed-phase (containing both ice and liquid) and were not used in this analysis. Additionally, $N_{\text {ice }}$ information from NIXE-CAPS was considered to aid us in determining in-cloud flight segments and for visualizing characteristics of the clouds that were sampled.

The classification scheme was also validated using a different method based only on the trajectory information from the CLaMS model and without the visual cues like those shown in Fig. 4. A trajectory is classified as liquid origin if (1) it contains ice at the beginning of the trajectory that does not dissipate before reaching the flight path, (2) if the first valid temperature of the trajectory is warmer than $235 \mathrm{~K}$, and (3) if the flight path at the time of observation is at a higher altitude than the $500 \mathrm{hPa}$ level. The trajectories classified as in situ must satisfy one of the following criteria: the trajectory does not contain ice water at the beginning, or if it does, it must first appear at a temperature colder than $235 \mathrm{~K}$ or must evaporate before the trajectory reaches the flight path if it began at a temperature warmer than $235 \mathrm{~K}$. Good agreement was observed between the classification used in this analysis and the trajectory-based scheme. This demonstrates the robustness of our classification.

Seven flights were found to contain in situ origin cirrus only and two flights contain liquid origin cirrus only. Four flights contain a combination of both origin categories and 

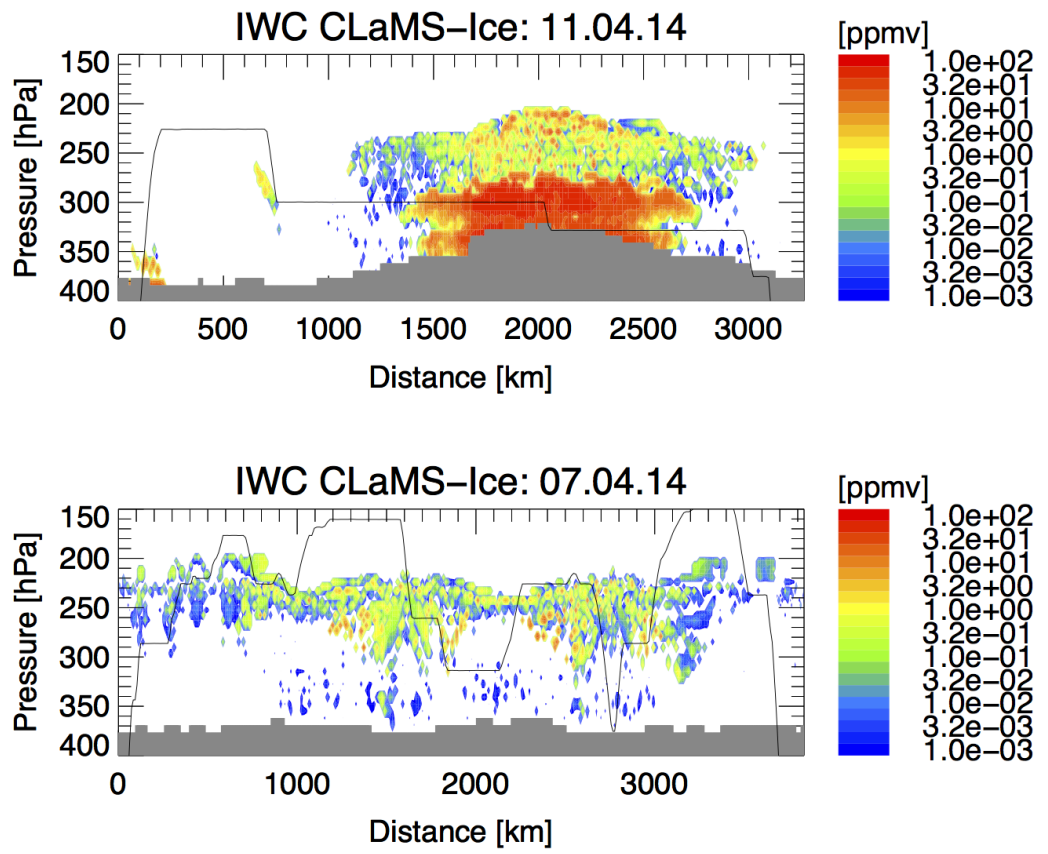

Figure 4. Examples of CLaMS-Ice simulations from ML-CIRRUS showing a liquid origin cloud sample (top) from the 11 April flight and an in situ origin sample (bottom) from the 7 April flight. The flight path is illustrated by the black line and represents the pressure at which the aircraft was flying ( $y$ axis) and the distance since take-off ( $x$ axis). The colors in each plot represent the simulated IWC (orange: high IWC, blue: low IWC). Grey areas indicate $T>238 \mathrm{~K}$ and do not contain simulated clouds.

have therefore been divided into respective segments. This information is listed in Table 1.

\section{Microphysical properties of in situ and liquid origin cirrus}

\subsection{IWC differences}

As stated in the introduction, our work until this point has focused primarily on the relationship between IWC and temperature. Thus, our first impressions of the ML-CIRRUS data set are also based on the observations of this relationship that were collected during this campaign. This is shown in Fig. 5 (in both ppmv and $\mathrm{g} \mathrm{m}^{-3}$ ) and includes 15 flights from ML-CIRRUS (the excluded flight does not contain data from NIXE-CAPS). The most frequently observed IWC values (darker colors in Fig. 5) as a function of temperature are generally found along the "core median" fit line, which was calculated based on the larger climatological data set found in Schiller et al. (2008). Also notable are the high IWC values $\left(>100\right.$ ppmv, or approximately $\left.>0.05 \mathrm{~g} \mathrm{~m}^{-3}\right)$ that were observed.

In comparison to another midlatitude data set, such as SPARTICUS, the most frequent values from ML-CIRRUS appear low. The range of IWC values found in SPARTICUS are between 0.001 and $0.4 \mathrm{~g} \mathrm{~m}^{-3}$ (Muhlbauer et al., 2014), while the values from ML-CIRRUS are found in a larger
Table 1. ML-CIRRUS flight dates and respective origin categorization. Classification as "combination" means that both in situ and liquid origin cirrus were observed. Some days contain more than one flight.

\begin{tabular}{ll}
\hline Date & Origin category \\
\hline $19 \mathrm{Mar}$ & In situ \\
$21 \mathrm{Mar}$ & In situ \\
$22 \mathrm{Mar}(1)$ & Liquid \\
$22 \mathrm{Mar}(2)$ & Liquid \\
$26 \mathrm{Mar}$ & In situ \\
$27 \mathrm{Mar}$ & Combination \\
$29 \mathrm{Mar}$ & Combination \\
$1 \mathrm{Apr}$ & In situ \\
$3 \mathrm{Apr}$ & In situ \\
$7 \mathrm{Apr}$ & In situ \\
$11 \mathrm{Apr}(1)$ & Combination \\
$11 \mathrm{Apr}(2)$ & Combination \\
$13 \mathrm{Apr}$ & In situ \\
\hline
\end{tabular}

range between $10^{-5}-0.2 \mathrm{~g} \mathrm{~m}^{-3}$. As a result, the definition of what is considered "low" and "high" IWC is different between our study and others. However, when the meteorology that was encountered during each campaign is considered, the reasons for differing IWC ranges is explained. The ML-CIRRUS data set does not contain the higher IWC values associated with anvil cirrus, while the SPARTICUS 

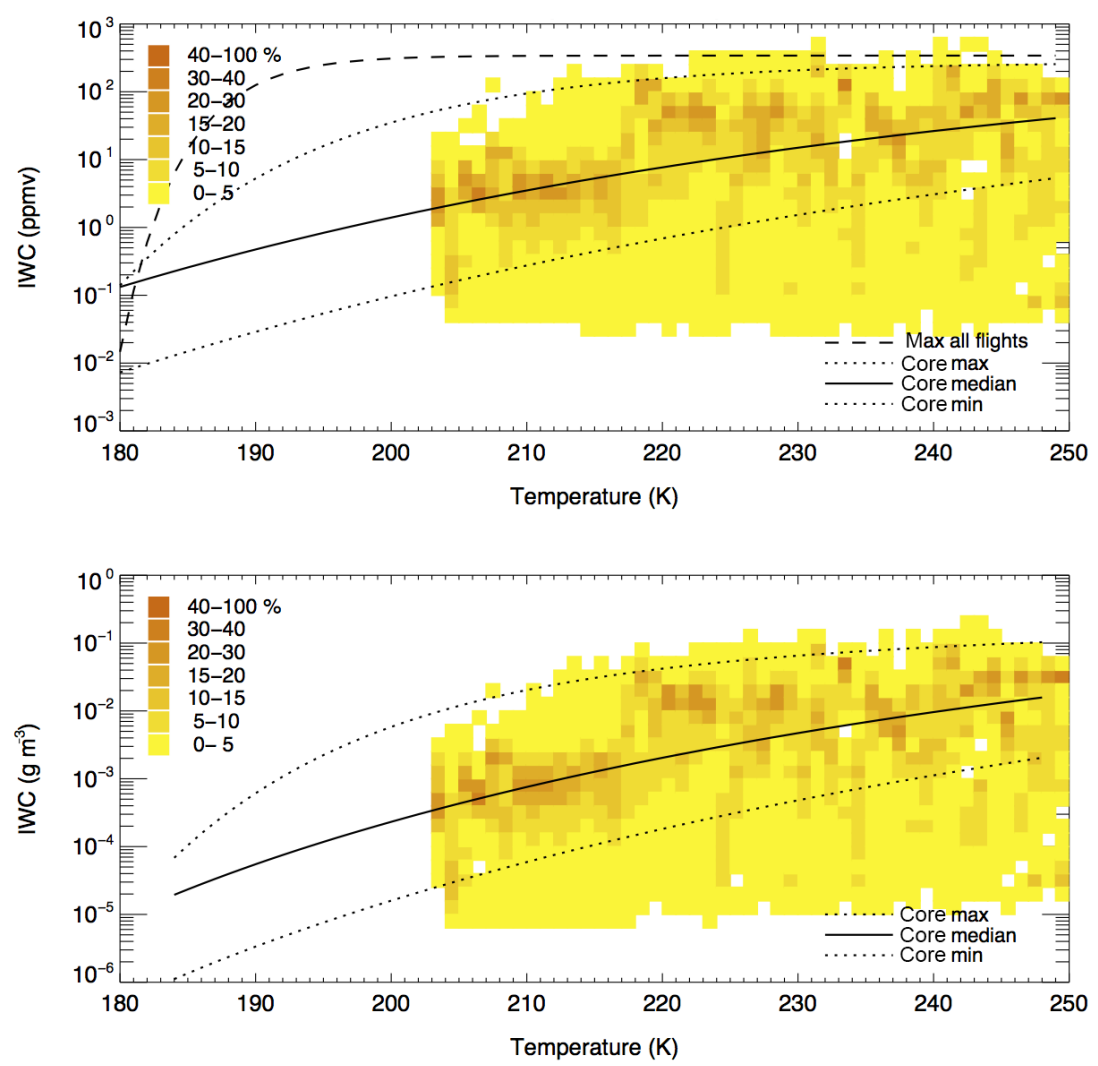

Figure 5. The frequency of IWC observations as a function of temperature for 15 flights from the ML-CIRRUS campaign. IWC is plotted in $1 \mathrm{~K}$ temperature bins and is show in ppmv (top) and $\mathrm{g} \mathrm{m}^{-3}$ (bottom). The core max, median, and core min lines (black) are from Schiller et al. (2008).

data set does not include observations of in situ origin cirrus in slow updrafts, which contributes the low IWC values $\left(<0.001 \mathrm{~g} \mathrm{~m}^{-3}\right)$. This is more thoroughly discussed in Krämer et al. (2016).

To explore the differences between these two cirrus types (in situ and liquid origin), we also begin with IWC as a function of temperature. As seen in Fig. 6, it is already possible to see that our hypothesis concerning the difference in IWC magnitude between the two origins can be demonstrated. Not only are the higher IWC values sorted into the liquid origin cirrus category, but the distribution is also different. As illustrated by the distribution relative to the median line, the most frequent IWC values found in liquid origin cirrus are higher than those observed in the in situ origin cirrus clouds. The next sections take a more detailed look at how the microphysics of the two cirrus types differ, the mechanisms that can potentially explain those differences, and underscore that two distinct cirrus types do indeed exist.

\subsection{IWC, $N_{\text {ice }}$, and $R_{\text {ice }}$}

While IWC, $N_{\text {ice }}$, and $R_{\text {ice }}$ are often investigated individually, this analysis considers all three variables together, as shown in Fig. 7a and b. This representation was first used in
Krämer et al. (2016), and Fig. 7a comes directly from their article. The plots show $N_{\text {ice }}$ as a function of $R_{\text {ice }}$ with the colors representing IWC. The black lines in the plot also denote IWC, but represent a value that is calculated using Eq. (2). Comparing the plots side by side, one of the most obvious differences is once again (as in Fig. 6) that the highest IWC values are found in the liquid origin cirrus. Also, the high IWCs occur in combination with higher $N_{\text {ice }}$ values than in the in situ origin cirrus, which is a key indicator of liquid origin cirrus. Additionally, the $R_{\text {ice values observed in the }}$ liquid origin cirrus cases occasionally exceed $100 \mu \mathrm{m}$ in radius, while the $R_{\text {ice }}$ values in the in situ origin cirrus cases begin to taper off above approximately $75 \mu \mathrm{m}$ in radius.

Another feature that should be noted is the high $N_{\text {ice }}$ values at small $R_{\text {ice }}$ and low IWC values that are exhibited in the in situ origin panel. These data are likely to be the result of aviation-induced cirrus (see also Krämer et al., 2016). Although they are also ice clouds, aviation-induced cirrus clouds (or contrails) develop in different environmental conditions than naturally occurring cirrus clouds and display different microphysical properties as a result. This includes lower IWC values, high $N_{\text {ice }}$, and quite small ice crystals between about 10 and $20 \mu \mathrm{m}$ in diameter. For that reason, it is more appropriate to consider and analyze this type of cirrus 

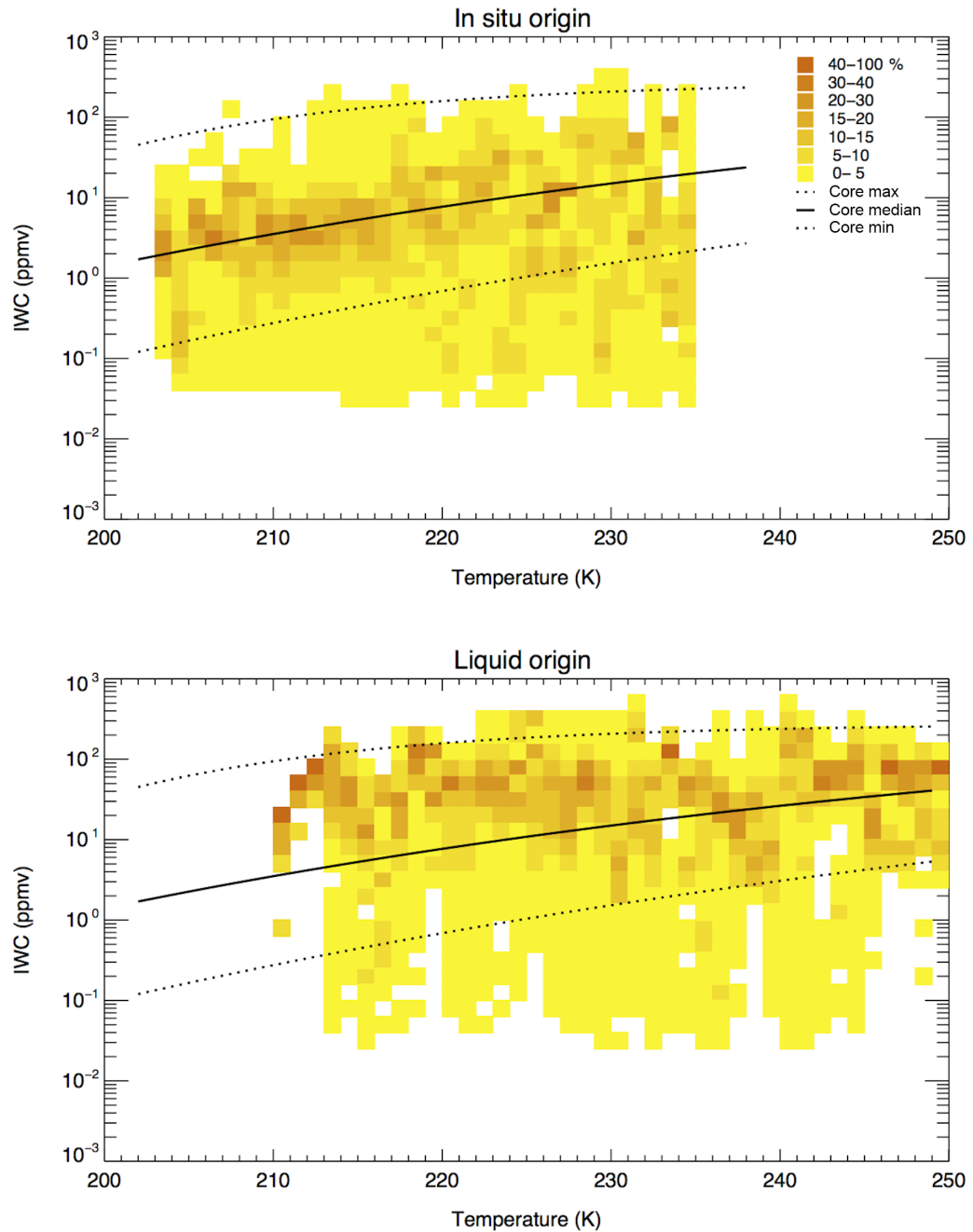

Figure 6. The frequency of IWC observations as a function of temperature. IWC is plotted in $1 \mathrm{~K}$ temperature bins for in situ origin (top) and liquid origin (bottom) data. The core max, median, and core min lines (black) are from Schiller et al. (2008).

separately. In the study presented here, aviation-induced cirrus were not filtered out due to the complexities of doing so, particularly since contrails are often embedded within naturally occurring cirrus. However, within the NIXE-CAPS ice crystal data set, there are some instances in which we can observe a strong contrail signal occurring during flight legs around $210 \mathrm{~K}$, which is the average temperature at the cruising altitude for commercial aircraft in the midlatitudes. Thus, we have an indication of which flights are more representative of aviation-induced cirrus as well as how the microphysical properties of those segments appear. Any strong features resembling those found in aviation-induced cirrus should be explored with some amount of caution as they may be the result of contrail samples.

From Fig. 7a and $\mathrm{b}$ alone it is difficult to say anything about the frequency with which these observations have occurred. For this purpose, we can look at Fig. 7c and d. The same information from Fig. 7a and $b$ is presented regarding
$N_{\text {ice }}$ and $R_{\text {ice }}$, except the colors represent the frequency of observation instead of IWC. However, the IWC information is not completely lost as the IWC lines provide a rough indication of the expected IWC. Here, the differences between these two cirrus types become more clear. Not only are the upper bounds of IWC and $R_{\text {ice }}$ reaching higher and larger values, respectively, in the liquid origin case, but the overall distribution is shifted to higher IWC, $N_{\text {ice }}$, and $R_{\text {ice }}$ values in terms of where the highest frequency observations are occurring. For example, the most frequently observed IWC for in situ origin cirrus are 1-10 ppmv, while the most common liquid origin cirrus IWCs lie between 10 and 100 ppmv. Also, for the same $N_{\text {ice }}$ value, $R_{\text {ice }}$ values are shifted to larger sizes in the liquid origin cirrus relative to the values in the in situ origin cirrus. 

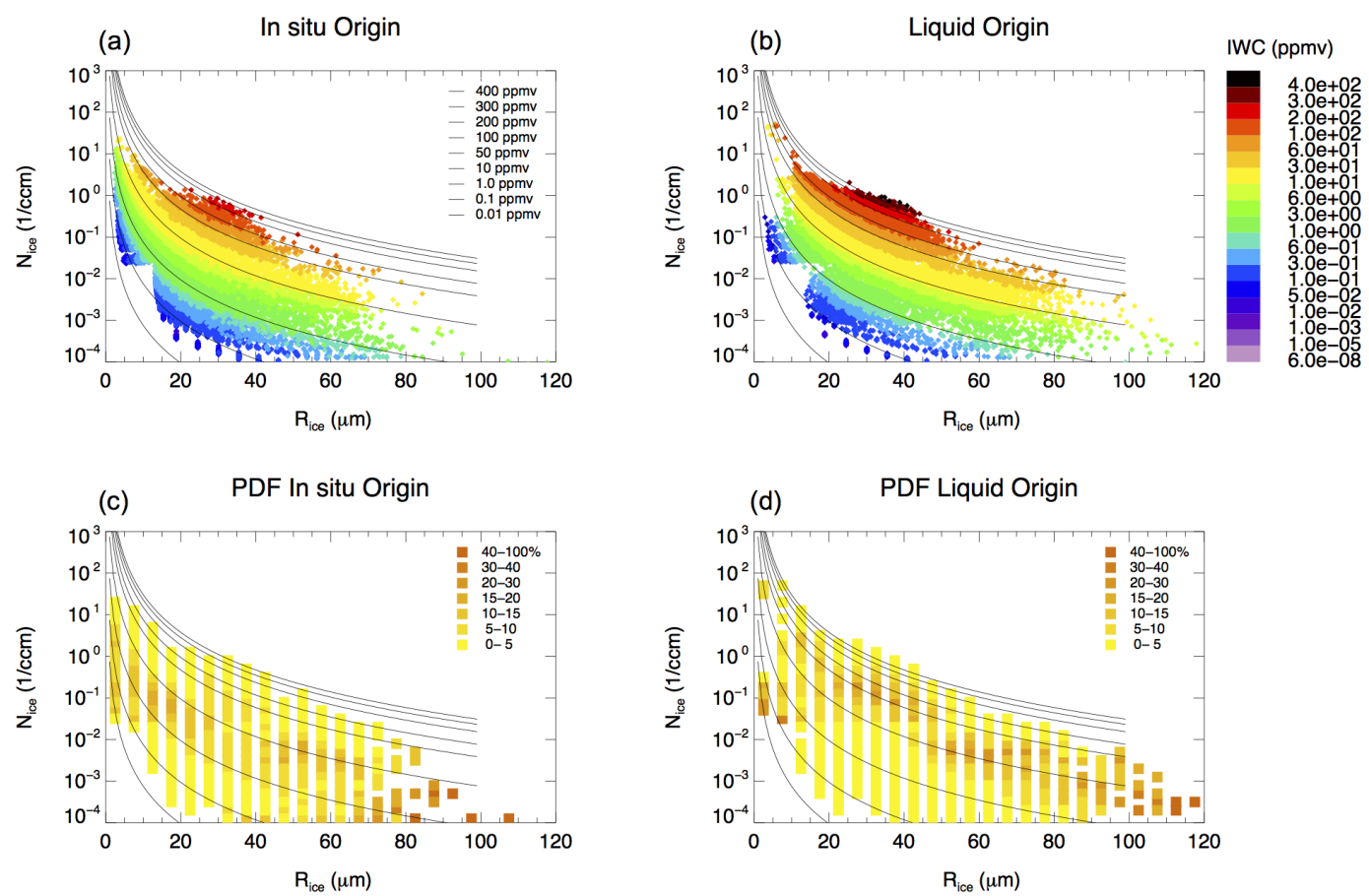

Figure 7. $N_{\text {ice }}$ as a function of $R_{\text {ice }}$ sorted by observed IWC. The solid black lines in all panels represent IWC levels as calculated by Eq. (2). (a, b) The colors indicate the IWC (in ppmv) that were observed for each observed $N_{\text {ice }}-R_{\text {ice }}$ combination. (c, d) The colors indicate the frequency of observation for each $N_{\text {ice }}-R_{\text {ice }}$ combination. The cutoff at small $R_{\text {ice }}$ and $N_{\text {ice }}<0.03 \mathrm{~cm}^{-3}$ represents the lower $N_{\text {ice }}$ detection limit of the CAS-DPOL when it is operated at $1 \mathrm{~Hz}$. Panel (a) is also shown in Krämer et al. (2016).
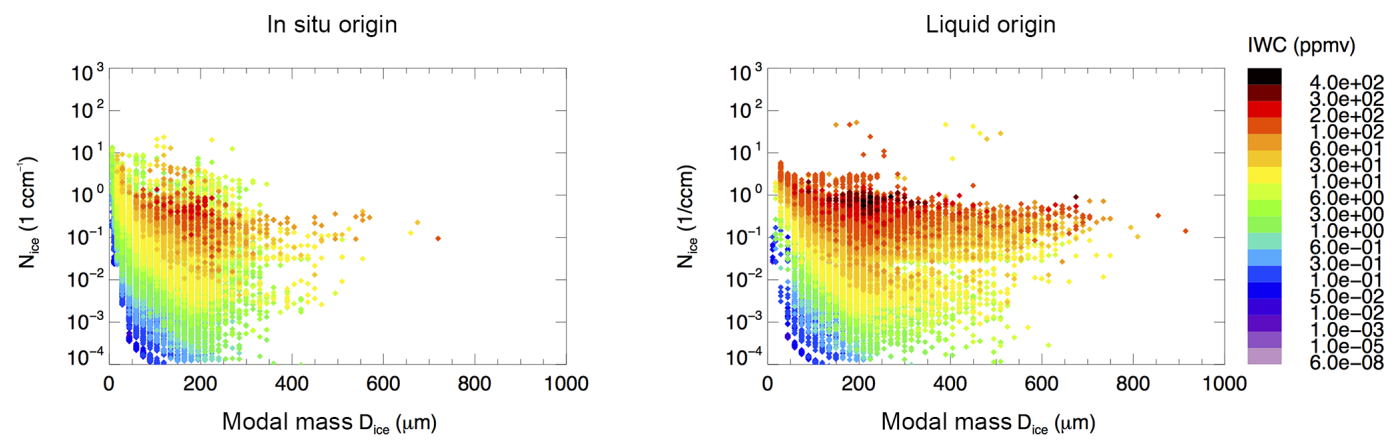

Figure 8. Same as Fig. 7a and b but with $D_{\text {ice, mode }}$ instead of $R_{\text {ice }}$.

\subsection{IWC, $N_{\text {ice, }}$, and $D_{\text {ice, mode }}$}

Another way of looking at the size of the particles is by considering the $D_{\text {ice, mode }}$ instead of $R_{\text {ice }}$. Figure 8 shows the same IWC and $N_{\text {ice }}$ as Fig. 7a and b, but now with $D_{\text {ice, mode }}$ as the size parameter. An advantage to looking at the sizes of the crystals contributing the most mass is that the differences between the cirrus types become more clear. For example, the fact that there are more high IWC values in the case of liquid origin cirrus than in the in situ origin cirrus becomes more obvious given the abundance of the orange and red colors. Also, we can see that $D_{\text {ice, mode }}$ values reach approximately $550 \mu \mathrm{m}$ in the in situ origin cirrus, but extend out to approxi-

mately $750 \mu \mathrm{m}$ for the liquid origin cirrus. This provides a visual link between the high IWCs and large crystals. Furthermore, a relationship between $N_{\text {ice }}$ and the range of $D_{\text {ice, mode }}$ values appears in the liquid origin cirrus. As $N_{\text {ice }}$ increases, the upper bound of $D_{\text {ice, mode }}$ also increases. For example, at $0.01 \mathrm{~cm}^{-3}$, the largest $D_{\text {ice, mode }}$ values are around $500 \mu \mathrm{m}$ while they are up to $750 \mu \mathrm{m}$ for concentrations of $0.5 \mathrm{~cm}^{-3}$. The relationship between size and concentration, as well as possible explanations for the PSDs in each origin type, are discussed in more detail in Sect. 4.4.2. 


\subsection{Ice crystal properties: vertical and temperature profiles of concentration and size}

We have already shown that there is a variability of IWC as a function of temperature and that there are differences in this variability and the magnitude of the IWC values between origin types. Also, we have determined that there are differences in the concentrations and sizes of the ice crystals. In the following sections, we examine the ice crystals in a profile format in order to better examine these differences, as well as look for information concerning the mechanisms involved.

\subsubsection{Vertical profiles}

Figure 9 illustrates the vertical profiles of $N_{\text {ice }}$ and $D_{\text {ice, mode }}$ for in situ origin cirrus and liquid origin cirrus. Median values of each variable were calculated for $500 \mathrm{~m}$ altitude intervals along with the lower and upper quartiles (horizontal lines). In Fig. 9a and b, it is clear that the $N_{\text {ice values in the }}$ liquid origin cirrus type are larger than those in the in situ origin cirrus type by up to nearly an order of magnitude depending on the altitude. The ranges between the lower (LQ) and upper quartiles (UQ) also reveal another difference. This range is larger for in situ origin cirrus than for most of the liquid origin cirrus. The median values in the liquid origin are consistently greater than the midlatitude modal value of $0.1 \mathrm{~cm}^{-3}$, which we use here as a guideline, whereas the in situ origin values are distributed around the modal value.

Figure $9 \mathrm{c}$ and $\mathrm{d}$ also demonstrate a clear difference between these origin types in terms of their $D_{\text {ice, mode. Nearly }}$ all of the median values in the in situ origin type are less than $200 \mu \mathrm{m}$, while the opposite is true in the liquid origin case. The range between the LQ and UQ is mostly narrower in the in situ origin cirrus compared to the liquid origin cirrus. As for trends in $D_{\text {ice, mode }}$ as a function of altitude, it is demonstrated there is not a clear trend for in situ origin cirrus, but $D_{\text {ice, mode }}$ is decreasing with increasing altitude in liquid origin cirrus, which is likely a result of sedimentation.

Another piece of information that becomes clear at this point is that while there is an overlap region in regard to altitude, the liquid origin cirrus can be found at the lower end of expected cirrus altitudes, while the in situ origin cirrus are found at higher altitudes. This result is not surprising considering our hypothesized development mechanism and the indications from the CLaMS-Ice model. It makes sense that the liquid origin cirrus have strong ties to lower regions in the atmosphere.

\subsubsection{PSDs as a function of temperature}

Further inferences about the formation and evolution of the clouds in each origin type can be made based on how the overall population of ice crystals is behaving as a function of temperature. Figure 10 shows a comparison between the PSDs in $5 \mathrm{~K}$ temperature bins observed in liquid ori-
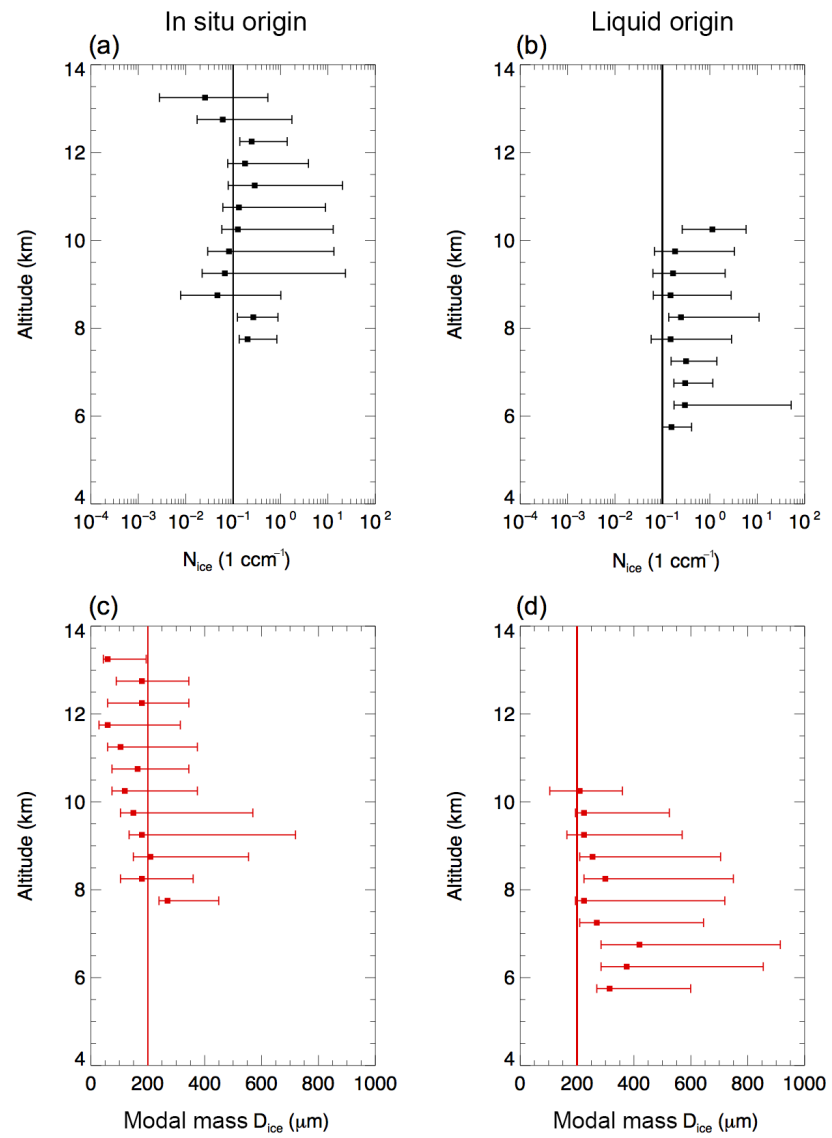

Figure 9. Vertical profiles of median values of $N_{\text {ice }}(\mathbf{a}, \mathbf{b})$ and $D_{\text {ice, mode }}(\mathbf{c}, \mathbf{d})$ for in situ origin $(\mathbf{a}, \mathbf{c})$ and liquid origin $(\mathbf{b}, \mathbf{d})$ cirrus. The horizontal bars represent the range from the lower quartile to the upper quartile. The black, vertical line at $0.1 \mathrm{~cm}^{-3}$ in a and b represents the modal $N_{\text {ice }}$ observed in midlatitude cirrus. The red, vertical line at $200 \mu \mathrm{m}$ in c and d was arbitrarily chosen as a reference for comparing the $D_{\text {ice, mode values. }}$

gin and in situ origin cirrus. For both origin cases, the general trend is that as the temperature increases, the number of small crystals decreases while the number of larger ice crystals increases, which is consistent with reports from other studies such as Boudala et al. (2002). Cirrus clouds are typically structured with small ice crystals at the top and large ice crystals at the bottom. The smallest crystals are found where nucleation is occurring. Larger crystals develop mostly through diffusional growth by water vapor and then fall to lower cloud layers and warmer temperatures as they grow. Of course, dynamics and processes like sedimentation are also important for determining the structure of a cirrus cloud, (e.g., Spichtinger and Gierens, 2009b). Nevertheless, despite the fact that PSDs from both origins fit this simplified description, clear differences remain.

The most obvious difference between the overall PSDs, is that the concentrations of both small and large crystals are greater overall in the liquid origin cirrus clouds (right 

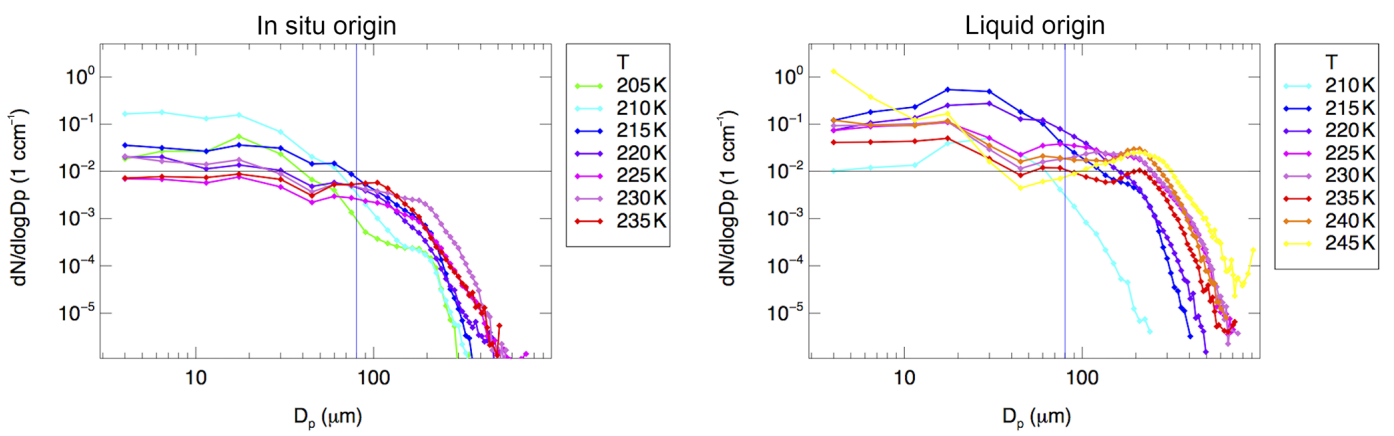

Figure 10. Particle size distributions of in situ origin cirrus (left) and liquid origin cirrus (right) for $5 \mathrm{~K}$ temperature bins. The temperatures listed in the key are the middle of the temperature bin. $D_{\mathrm{p}}$ : optical equivalent diameter for CAS-DPOL, area equivalent diameter for CIPGrayscale $\left(D_{\mathrm{p}}>20 \mu \mathrm{m}\right)$.

panel, Fig. 10). This is consistent with the observations that have been discussed in regard to the previous figures. The other clear difference is that the PSD range in the liquid origin cirrus reaches higher ice crystal diameters $\left(D_{\mathrm{p}}\right)$. Excluding the PSD at $210 \mathrm{~K}$, which contains a smaller number of data points, the upper limit of the $D_{\mathrm{p}}$ range in the liquid origin cirrus clouds goes from $400-1000 \mu \mathrm{m}$ as the temperature increases while the in situ origin clouds reach only 300 $700 \mu \mathrm{m}$.

If we consider the origin of the ice crystals, the reasons for the differences between the PSDs become more clear. For example, though the liquid origin cirrus PSDs are structured similarly to the in situ origin PSDs, they are in fact also consistent with what is observed in ice crystal PSDs from glaciated mixed-phase clouds (to be demonstrated in an upcoming analysis). As explained in Sect. 2, the ice particles in glaciated mixed-phase clouds stem from heterogeneous drop freezing. Thus, the higher overall concentrations of cloud particles is indicative of the abundance of active ice nuclei (IN) lower in the atmosphere where the crystals first formed (see Krämer et al., 2016, for more detailed discussion). In the observations used here, we have not found evidence that homogeneous drop freezing also contributed to the development of the liquid origin PSDs, which would have resulted in even higher overall concentrations. The lack of this feature in our data is likely due to the fact that the strong convection necessary for producing such events is not typically found over Europe.

However, the result of a subsequent homogeneous ice nucleation event (a second nucleation event after heterogeneous nucleation has already taken place) can be observed. The liquid origin PSDs at 215 and $220 \mathrm{~K}$ both show an increased concentration of small particles around $20 \mu \mathrm{m}$. This feature can be traced back to a strong homogeneous ice nucleation event that was sampled during the flight on 29 March. Figure 11 shows a time series of the PSDs observed by the NIXE-CAPS during this flight. Additional information concerning temperature and pressure as well as RH (with respect to water and ice) from the BAHAMAS and SHARC instruments, respectively, is also presented. Two passes into the homogeneous ice nucleation event were made between 16:50 and $17: 10$, one at $215 \mathrm{~K}$ followed by another at $220 \mathrm{~K}$. High $\mathrm{RH}_{\text {ice }}$ up to $150 \%$ and $N_{\text {ice }}$ as high as $5 \mathrm{~cm}^{-3}$ were observed during the event, which are both a good indication of homogeneous ice nucleation, (e.g., Barahona and Nenes, 2009). As evidenced by the yellows and oranges, there was an increase in the concentration of small particles at these points, which is consistent with the increased concentrations in the PSD in Fig. 10.

It is also possible that subsequent homogeneous ice nucleation contributed to the in situ origin cirrus, but such strong, visible indications are not observed in the PSDs from MLCIRRUS. The high concentrations of the smallest crystals seen at $210 \mathrm{~K}$ in the in situ origin cirrus (left panel, Fig. 10) are attributable to aviation-induced cirrus, not homogeneous ice nucleation. Overall, the lower concentrations of ice crystals in the in situ origin cirrus relative to the liquid origin cirrus are indicative that the number of available IN might be lower (see Krämer et al., 2016, for more detailed discussion). Furthermore, in cases of homogeneous ice nucleation, $N_{\text {ice }}$ is unlikely to be enhanced to the same degree as was observed during the 29 March flight.

The difference in sizes between the largest crystals observed in each origin type is likely to be the result of the more desirable growth conditions found in the mixed-phase regime (i.e., more water vapor). Also, it is possible for the ice crystals to continue growing after arriving in the cirrus regime. When the air parcel is lifted already containing many large crystals, they will continue to grow by diffusion, if the concentration is low and the air is supersaturated, or by aggregation when the concentration is high. In comparison, in situ origin cirrus development essentially starts from the beginning. Cirrus clouds with a liquid origin have a PSD to begin with and build upon.

The classification of PSDs in this study by cirrus origin type is something that has not been done before. In addition, 


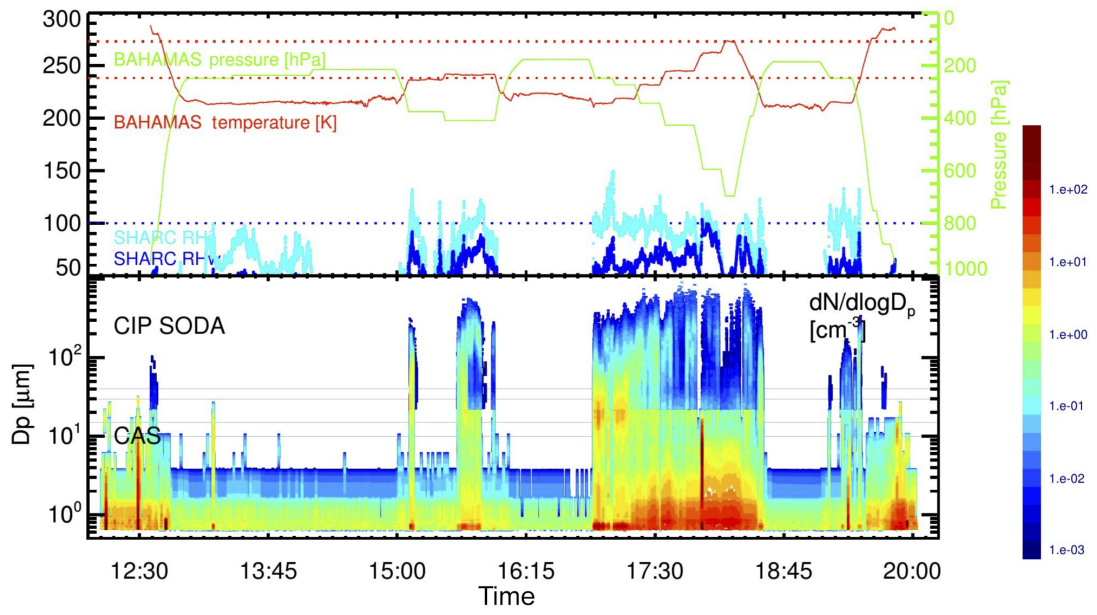

Figure 11. Time series example from flight on 29 March demonstrating the observation of a homogeneous ice nucleation event in a liquid origin cirrus cloud. The top panel of the figure shows the atmospheric data for the flight - time (red), pressure (green), $\mathrm{RH}_{\mathrm{ice}}(\mathrm{turquoise})$, and $\mathrm{RH}_{\text {water }}$ (blue). The bottom panel shows the PSD observed by the NIXE-CAPS (diameter is on the $y$ axis, time is on the $x$ axis). The colors indicate the concentration of particles $\left(\mathrm{d} N / \mathrm{d} \log D_{\mathrm{p}}\right.$ in $\left.\mathrm{cm}^{-3}\right)$.

many older measurements are influenced by shattering artifacts. Furthermore, differences in instrumentation, data processing/analysis techniques, and the conditions in which observations were made also exist between data sets, thus making it difficult to draw a good comparison between the PSDs presented in Fig. 10 and previous studies.

Overall, the ice crystal concentrations in the PSDs from ML-CIRRUS are low throughout the sampled temperature range relative to PSDs from other midlatitude observations made by, e.g., Jackson et al. (2015), Jensen et al. (2013), and Lawson et al. (2006). In the case of the Jensen et al. (2013) measurements, two PSDs that are provided in the analysis come from observations of convective outflow (typical for that data set). In comparison to both the case of in situ and liquid origin cirrus, the concentrations from the convective case are higher, which is expected given that this is not a dynamic situation that was observed during ML-CIRRUS.

The observations reported in Jackson et al. (2015) concerning the SPARTICUS campaign (also found in Muhlbauer et al., 2014) result in a similar findings, but is perhaps a more appropriate comparison since their observations have been classified as either "synoptic" or "convective". The in situ origin cirrus concentrations in our study are within the range of the synoptic concentrations from SPARTICUS, but still consistently below the median values for all temperatures. The comparison between the liquid origin and convective cirrus shows better agreement between 219 and $233 \mathrm{~K}$, but is again lower for the warmer temperatures. These differences could be attributed to, (i) differences in the way that the data was categorized, or, (ii) differences in the observed dynamics as noted earlier. The difference in categorization could mean, for example, that clouds we would classify as liquid origin (e.g., lee wave, warm conveyor belt), which have the associated high IWC and high $N_{\text {ice }}$, are being classified in Jackson et al. (2015) as synoptic cirrus. Another consistent and notable feature from the SPARTICUS data in comparison to the PSDs shown here, are the high concentrations of large particles, which was also not seen in ML-CIRRUS.

A third comparison to a data set from Lawson et al. (2006) demonstrates an overall better comparison in regard to ice crystal concentrations than the previous two. In this case, the cirrus observations only come from synoptically generated cirrus, but could also be orographically enhanced. It should be noted that the very high concentrations of small particles in the Lawson et al. (2006) PSDs are suggested to be the result of shattering, and are therefore not considered in the comparison here. In the three temperature ranges (210-223, 224-233, and 234-243 K), the median concentration values in the lowest temperature range in Lawson et al. (2006) agree well with the in situ origin PSD from Fig. 10, while the middle and highest temperature range compare better to the liquid origin PSD. Considering the vertical distributions of in situ and liquid origin cirrus shown in Fig. 9 and that it is possible for "synoptic" to include liquid origin cirrus, this result is not surprising. In general, the comparisons that we have made demonstrate how using a formation-based classification versus the more traditional meteorology-based ones can result in differences expressed in the PSDs.

\section{Comparisons to MidCiX}

Despite having a clear picture of the properties associated with the two cirrus origin types, there are questions concerning whether they are also found in other locations and regions, i.e., how cirrus produced by other meteorological situations (e.g., anvil outflow cirrus) fit in to this classifi- 

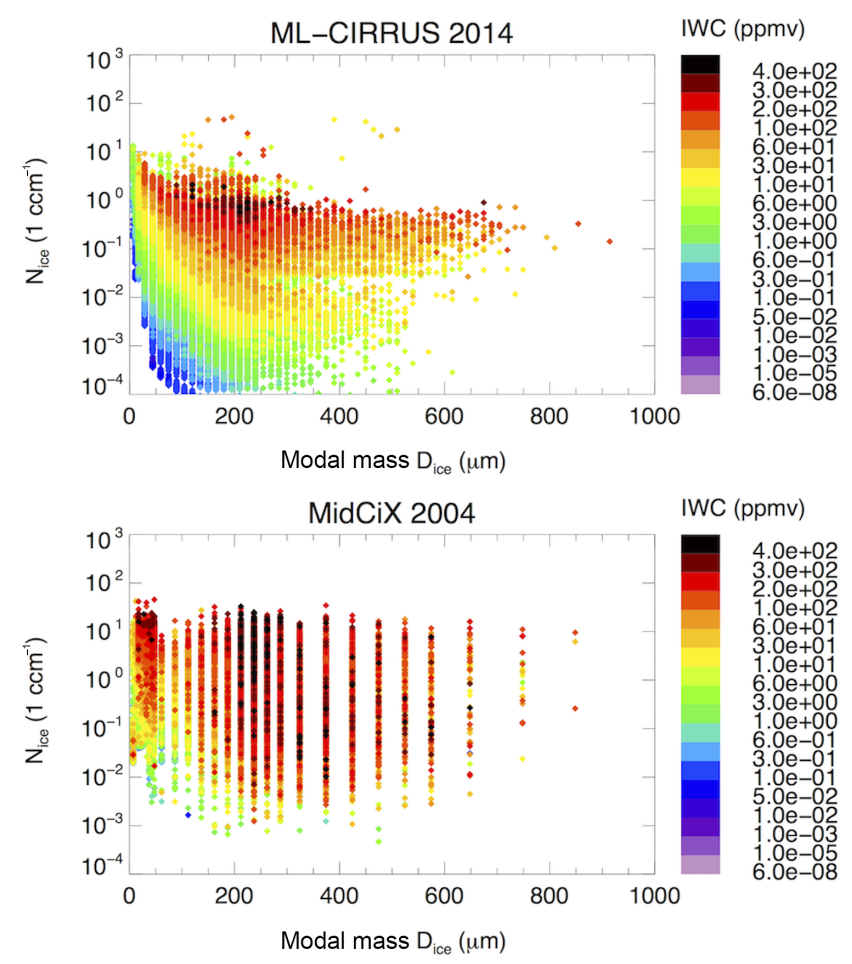

Figure 12. Same as Fig. 8 but for all 13 ML-CIRRUS flights (both in situ and liquid origin; top) and MidCiX (bottom). The blank spaces between sizes are due to the merged bins for MidCiX.

cation scheme, and if the frequency with which they occur is similar. In an effort to begin exploring this idea, we have compared the results from ML-CIRRUS to the data from the Midlatitude Cirrus eXperiment (MidCiX), which took place in the spring of 2004 and was based out of Houston, Texas. Figure 12 shows the relationships between IWC, $N_{\text {ice }}$, and $D_{\text {ice, mode }}$ in the same format as Fig. 8 for each campaign. The top panel shows the observations from the ML-CIRRUS campaign without any division between in situ and liquid origin cirrus. The bottom panel shows data from the MidCiX campaign. For this campaign, the IWC values were measured by the Closed-path Laser Hygrometer (CLH) from the University of Colorado (Davis et al., 2007), while the $N_{\text {ice }}$ and

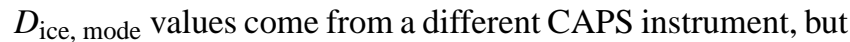
they also cover a similar size range as NIXE-CAPS. It is interesting to compare these two campaigns because they are representative of different dynamics. The MidCiX campaign took place in the springtime when the large scale dynamics in the US are shifting from the winter frontal systems to the summer convective systems. As a result, this data set is representative of cirrus stemming from jet streams, convection, and closed low pressure systems.
It can be seen in Fig. 12 that there is a difference in IWC, $N_{\text {ice }}$, and $D_{\text {ice, mode values. The MidCiX IWC content values }}$ are much larger overall and appear at larger $D_{\text {ice, mode }}$ than in ML-CIRRUS. Also, these large IWC values are observed at both low and high $N_{\text {ice. }}$. From this comparison, we hypothesize, that conditions with more prevalent convection will lead to more liquid origin cirrus with higher IWC values. However, the very high $N_{\text {ice }}$ values reported by the CAPS could be an overestimation caused by ice crystal shattering. This data set has not been corrected by an interarrival-time-based algorithm for such features. Instead, the concentrations of the particles in the overlapping ranges of the CAS and CIP probes incorporated into the CAPS have been adjusted to each other (see Krämer et al., 2016, for more details). However, an overestimation of $N_{\text {ice }}$ does not change the important message conveyed by this comparison in regard to the high IWC and

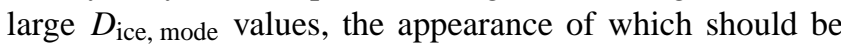
mostly unaffected by shattering.

Unfortunately, due to the important small scale features in these dynamic systems, the CLaMs-Ice model was unable to accurately portray each MidCiX flight, and therefore, we do not currently have the same information with respect to where the appropriate divisions between in situ origin and liquid origin cirrus cases should be. Although we cannot demonstrate it in the current analysis, we suspect that in Mid$\mathrm{CiX}$, and other campaigns sampling from similar dynamics, the liquid origin cirrus clouds are more prevalent relative to the in situ origin cirrus clouds than what is observed in the ML-CIRRUS data set. Further analysis and additional data, which can be found in an upcoming analysis, are necessary to answer this critical question.

\section{Distribution of in situ and liquid origin cirrus}

The differences between the cirrus cloud origins that have been described here offer new insights into how cirrus can be classified. To demonstrate that two groups do in fact exist within one campaign data set, Fig. 13 shows the IWC-temperature relationship from ML-CIRRUS. Similar to Fig. 6 , the data are presented in $5 \mathrm{~K}$ temperature bins and provide information on the frequency with which each variable occurs within a given temperature bin. Furthermore, the percentage by which each point is more representative of in situ origin cirrus (greens) or liquid origin cirrus (blues) is also shown here. The most frequent observations at low IWC are at low temperatures and are predominantly in situ origin cirrus while the most frequent observations at warmer temperatures are predominantly liquid origin cirrus and exhibit high IWC values. There is an overlap region in the mid-range temperatures where in situ origin cirrus becomes less prevalent and liquid origin cirrus becomes increasingly dominant, but there is still a distribution around the median fit line of the IWC-T relationship. It can be argued that at $T>235 \mathrm{~K}$ the data will show $100 \%$ liquid origin because we have se- 


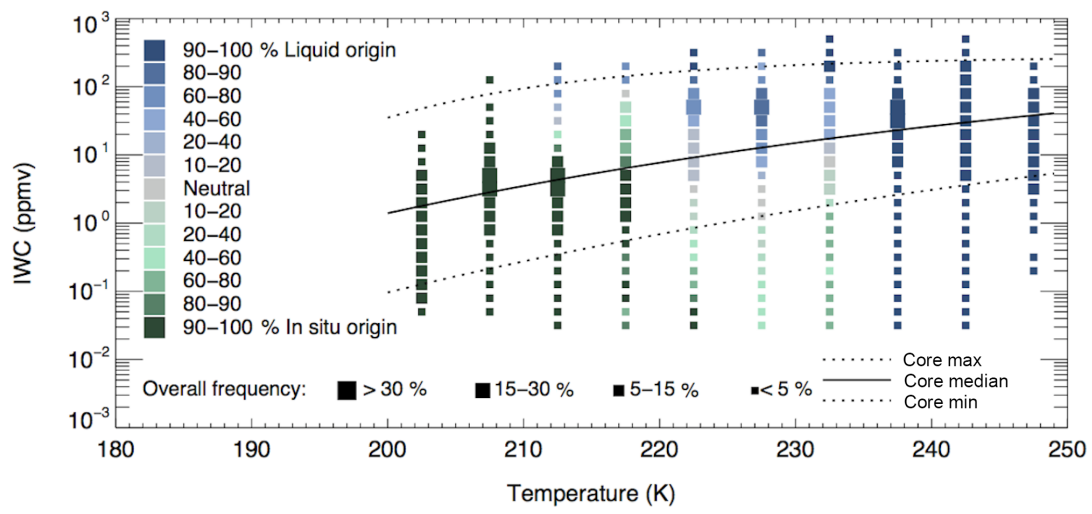

Figure 13. Probability distribution of IWC as a function of temperature for ML-CIRRUS. The size of the points represent the frequency of occurrence of each value within a $5 \mathrm{~K}$ temperature bin, similar to the data shown in Fig. 6 . The colors represent the percentage by which each point is more representative of in situ origin cirrus (greens) or liquid origin cirrus (blues). The maximum, core max, median, and core min lines (black) are from Schiller et al. (2008).

lected for it in the data processing, but this is not true for $T<235 \mathrm{~K}$.

The emergence of two distinct groups of cirrus clouds is reminiscent of the bimodal IWC distribution from Luebke et al. (2013) mentioned in the introduction, particularly since one group is more representative of low IWC, while the other is more representative high IWC. Thus, after completing this analysis, we now hypothesize that the two modes are the result of the presence of the two origin types. However, the heterogeneous and homogeneous ice nucleation mechanisms are still highly influential in driving the microphysical development of a cirrus cloud and will be discussed further in future work.

Finally, classifying the data in this way could be more accurate for representing cirrus clouds in the climate system because it includes the potential for also classifying the clouds according to their radiative role. The distribution shown in Fig. 13 appears very similar to what is shown in Fig. 11 in Krämer et al. (2016). Further analysis is planned to evaluate this as well.

\section{Conclusions}

The analysis presented here has expanded upon Luebke et al. (2013) and Krämer et al. (2016) by showing that cirrus clouds can be divided into two groups according to the origin of their ice particles. Here, we have used airborne, in situ observations of IWC, $N_{\text {ice }}$, and ice crystal size from the $2014 \mathrm{ML}-$ CIRRUS campaign to demonstrate clear differences between the microphysical properties of each origin type. Notably, we demonstrate that observations of high IWC and $N_{\text {ice values }}$ in combination with large crystals are found in the liquid origin cirrus type. The highest frequency IWC values for in situ origin cirrus were observed to be between 1 and $10 \mathrm{ppmv}$, while they were 10-100 ppmv in the liquid origin cirrus. The $N_{\text {ice }}$ values appear to be similar between the origin types, but median values demonstrate that there is a difference. Us-

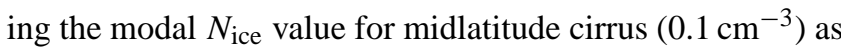
a guideline, it was found that median values of $N_{\text {ice }}$ for in situ cirrus are distributed around this value, but liquid origin cirrus clouds are above it. Similar to IWC, ice crystal size (both $R_{\text {ice }}$ and $D_{\text {ice, mode }}$ ) proved to also show distinct differences dependent on origin. $D_{\text {ice, mode }}$ in the in situ origin clouds had median values that were mostly less than $200 \mu \mathrm{m}$ with the largest particles reaching sizes of $550 \mu \mathrm{m}$. Ice crystals in the liquid origin cirrus had median $D_{\text {ice, mode values }}$ that were larger than the $200 \mu \mathrm{m}$ guideline and even larger crystals of nearly $750 \mu \mathrm{m}$.

PSDs in $5 \mathrm{~K}$ temperature bins allowed a more in-depth look at the details of the cloud structures based on the different populations of ice crystals and how they change with temperature. Once again, it was clear that differences exist between the concentrations and sizes of the particles. In particular, as noted throughout this analysis, the liquid origin cirrus could be characterized by higher concentrations of particles and a size range that is noticeably broader and containing larger crystals. From this information combined with the existing knowledge concerning the details of cloud development in the cirrus environment versus lower in the atmosphere (mixed-phase regime), we could infer the mechanisms and conditions that contributed to create the PSD for each origin type. This indicates that the origin of the ice crystal matters and the influence of that origin can be observed. Moreover, an example was given demonstrating how the PSD for a liquid origin cirrus cloud can continue to be built upon through subsequent homogeneous ice nucleation after arriving in the cirrus regime.

The concept that the two different formation-based cirrus types have different microphysical properties has been demonstrated based on the observations from the midlatitude field campaign ML-CIRRUS. However, this campaign may not be representative of the midlatitudes as a whole. The 
cloud observations mostly took place in moderate updrafts, typical for the region over Europe that was probed during the campaign. A comparison between the results from MLCIRRUS and MidCiX provides evidence to suggest that different dynamics will influence the relative frequency of occurrence of in situ versus liquid origin cirrus. Faster updrafts (e.g., convection) will result in higher IWCs and a larger influence from liquid origin cirrus, as demonstrated by the MidCiX data set. One of the uncertainties still existing within the work that is presented here is what the ratio of in situ to liquid origin clouds is on a local or even global scale. Thus, it would be informative to also analyze additional data from locations such as North America and Asia, where the dynamics are known to be more convective than what is typically observed over Europe.

The existence of these two cirrus groups also leads us to examine how we define a cirrus cloud. The major identifier of a cirrus cloud is that it is composed solely of ice. Other measurable properties may be assigned to different cloud samples to tell us more about the position, thickness, etc. of the cloud. However, as Lynch et al. (2002) suggest, sub-classifications of cirrus based on their ice content would be useful. Information concerning the origin of an ice crystal and how that influences the microphysical properties of a cirrus cloud is something that moves our understanding of cirrus in a direction that begins to provide a more clear representation of the radiative role of cirrus clouds. As stated by the 2013 IPCC report (Boucher et al., 2013), there remains a very large uncertainty in the role of ice clouds in the atmosphere. Simply put, it is unclear whether ice clouds have a warming or cooling effect on the atmosphere. Krämer et al. (2016) suggest that in situ origin cirrus clouds may have the tendency toward a cooling effect, while the thicker liquid origin clouds may tend toward warming. Future work is planned to address this topic. While these clouds will be called "cirrus" in any case, the study presented here demonstrates that a categorization scheme based on the two origins is more appropriate for describing the variety of cirrus clouds.

Acknowledgements. The authors are grateful to the teams involved in the ML-CIRRUS and MidCiX campaigns. Specifically we acknowledge the coordinators: Christiane Voigt, Andreas Minkin, and Ulrich Schumann for ML-CIRRUS and Gerald Mace and Andy Heymsfield for MidCiX. Funding was partly provided by the DFG HALO-SPP ACIS project (KR 2957/1-1). We would also like to thank Martin Zöger for providing BAHAMAS and SHARC data from ML-CIRRUS.

The article processing charges for this open-access publication were covered by a Research

Centre of the Helmholtz Association.

Edited by: E. Jensen

\section{References}

Barahona, D. and Nenes, A.: Parameterizing the competition between homogeneous and heterogeneous freezing in ice cloud formation - polydisperse ice nuclei, Atmos. Chem. Phys., 9, 59335948, doi:10.5194/acp-9-5933-2009, 2009.

Baumgardner, D., Jonsson, H., Dawson, W., O'Connor, D., and Newton, R.: The cloud, aerosol and precipitation spectrometer: a new instrument for cloud investigations, Atmos. Res., 59-60, 251-264, doi:10.1016/S0169-8095(01)00119-3, 2001.

Baumgardner, D., Newton, R., Krämer, M., Meyer, J., Beyer, A., Wendisch, M., and Vochezer, P.: The cloud particle spectrometer with polarization detection (CPSPD): a next generation open-path cloud probe for distinguishing liquid cloud droplets from ice crystals, Atmos. Res., 142, 2-14, doi:10.1016/j.atmosres.2013.12.010, 2014.

Boucher, O., Randall, D., Artaxo, P., Bretherton, C., Feingold, G., Forster, P., Kerminen, V.-M., Kondo, Y., Liao, H., Lohmann, U., Rasch, P., Satheesh, S., Sherwood, S., Stevens, B., and Zhang, X.: Clouds and Aerosols, in: Climate Change 2013: The Physical Science Basis. Contribution of Working Group I to the Fifth Assessment Report of the Intergovernmental Panel on Climate Change, Cambridge University Press, Cambridge, UK and New York, NY, USA, 2013.

Boudala, F. S., Isaac, G. A., Fu, Q., and Cober, S. G.: Parameterization of effective ice particle size for high-latitude clouds, Int. J. Climatol., 22, 1267-1284, doi:10.1002/joc.774, 2002.

Davis, S. M., Hallar, A. G., Avallone, L. M., and Engblom, W.: Measurement of total water with a tunable diode laser hygrometer: inlet analysis, calibration procedure, and ice water content determination, J. Atmos. Ocean. Tech., 24, 463-475, doi:10.1175/JTECH1975.1, 2007.

Erfani, E. and Mitchell, D. L.: Developing and bounding ice particle mass- and area-dimension expressions for use in atmospheric models and remote sensing, Atmos. Chem. Phys., 16, 43794400, doi:10.5194/acp-16-4379-2016, 2016.

Field, P. R., Heymsfield, A. J., and Bansemer, A.: Shattering and particle interarrival times measured by optical array probes in ice clouds, J. Atmos. Ocean. Tech., 23, 1357-1371, doi:10.1175/JTECH1922.1, 2006.

Heymsfield, A. J., Lewis, S., Bansemer, A., Iaquinta, J., Miloshevich, L. M., Kajikawa, M., Twohy, C., and Poellot, M. R..: A general approach for deriving the properties of cirrus and stratiform ice cloud particles, J. Atmos. Sci., 59, 3-29, 2002.

Heymsfield, A. J. and McFarquhar, G. M.: High albedos of cirrus in the tropical Pacific warm pool: microphysical interpretations from CEPEX and from Kwajalein, Marshall Islands, J. Atmos. Sci., 53, 2424-2451, doi:10.1175/15200469(1996)053<2424:HAOCIT>2.0.CO;2, 1996.

Heymsfield, A. J., Schmitt, C., and Bansemer, A.: Ice cloud particle size distributions and pressure-dependent terminal velocities from in situ observations at temperatures from $0^{\circ}$ to $-86^{\circ}$ C, J. Atmos. Sci., 70, 4123-4154, doi:10.1175/JAS-D-120124.1, 2013.

Jackson, R. C., McFarquhar, G. M., Fridlind, A. M., and Atlas, R.: The dependence of cirrus gamma size distributions expressed as volumes in $N_{0}-\lambda-\mu$ phase space and bulk cloud properties on environmental conditions: Results from the Small Ice Particles in Cirrus Experiment (SPARTICUS), J. Geophys. Res.-Atmos., 120, 10351-10377, doi:10.1002/2015JD023492, 2015. 
Jensen, E. J., Kinne, S., and Toon, O. B.: Tropical cirrus cloud radiative forcing: sensitivity studies, Geophys. Res. Lett., 21, 20232026, doi:10.1029/94GL01358, 1994.

Jensen, E. J., Lawson, R. P., Bergman, J. W., Pfister, L., Bui, T. P., and Schmitt, C. G.: Physical processes controlling ice concentrations in synoptically forced, midlatitude cirrus, J. Geophys. Res.-Atmos., 118, 5348-5360, doi:10.1002/jgrd.50421, 2013.

Joos, H., Spichtinger, P., Reutter, P., and Fusina, F.: Influence of heterogeneous freezing on the microphysical and radiative properties of orographic cirrus clouds, Atmos. Chem. Phys., 14, 68356852, doi:10.5194/acp-14-6835-2014, 2014.

Konopka, P., Günther, G., Müller, R., dos Santos, F. H. S., Schiller, C., Ravegnani, F., Ulanovsky, A., Schlager, H., Volk, C. M., Viciani, S., Pan, L. L., McKenna, D.-S., and Riese, M.: Contribution of mixing to upward transport across the tropical tropopause layer (TTL), Atmos. Chem. Phys., 7, 3285-3308, doi:10.5194/acp-7-3285-2007, 2007.

Korolev, A. and Sussman, B.: A technique for habit classification of cloud particles, J. Atmos. Ocean. Tech., 17, 1048-1057, doi:10.1175/1520-0426(2000)017<1048:ATFHCO>2.0.CO;2, 2000.

Krämer, M., Schiller, C., Afchine, A., Bauer, R., Gensch, I., Mangold, A., Schlicht, S., Spelten, N., Sitnikov, N., Borrmann, S., de Reus, M., and Spichtinger, P.: Ice supersaturations and cirrus cloud crystal numbers, Atmos. Chem. Phys., 9, 3505-3522, doi:10.5194/acp-9-3505-2009, 2009.

Krämer, M., Rolf, C., Luebke, A., Afchine, A., Spelten, N., Costa, A., Meyer, J., Zöger, M., Smith, J., Herman, R. L., Buchholz, B., Ebert, V., Baumgardner, D., Borrmann, S., Klingebiel, M., and Avallone, L.: A microphysics guide to cirrus clouds - Part 1: Cirrus types, Atmos. Chem. Phys., 16, 3463-3483, doi:10.5194/acp16-3463-2016, 2016.

Lawson, R. P., Baker, B., Pilson, B., and Mo, Q.: In Situ Observations of the Microphysical Properties of Wave, Cirrus, and Anvil Clouds. Part II: Cirrus Clouds, J. Atmos. Sci., 63, 3186-3203, doi:10.1175/JAS3803.1, 2006.

Lawson, R. P., Jensen, E., Mitchell, D. L., Baker, B., Mo, Q., and Pilson, B.: Microphysical and radiative properties of tropical clouds investigated in TC4 and NAMMA, J. Geophys. Res.Atmos., 115, D00J08, doi:10.1029/2009JD013017, 2010.

Luebke, A. E., Avallone, L. M., Schiller, C., Meyer, J., Rolf, C., and Krämer, M.: Ice water content of Arctic, midlatitude, and tropical cirrus - Part 2: Extension of the database and new statistical analysis, Atmos. Chem. Phys., 13, 6447-6459, doi:10.5194/acp13-6447-2013, 2013.

Lynch, D. K., Sassen, K., Starr, D. O., and Stephens, G. (Eds.): Cirrus, Oxford University Press, Inc., Oxford, UK, 2002.

McKenna, D. S., Grooß, J.-U., Günther, G., Konopka, P., Müller, R., Carver, G., and Sasano, Y.: A new chemical lagrangian model of the stratosphere (CLaMS) 2. Formulation of chemistry scheme and initialization, J. Geophys. Res.-Atmos., 107, ACH4.1ACH4.14, doi:10.1029/2000JD000113, 2002.
Meyer, J.: Ice Crystal Measurements with the New Particle Spectrometer NIXE-CAPS, Schriften des Forschungszentrum Jülich, Reihe Energie und Umwelt, 160, 2012.

Mitchell, D. L., d'Entremont, R. P., and Lawson, R. P.: Inferring cirrus size distributions through satellite remote sensing and microphysical databases, J. Atmos. Sci., 67, 1106-1125, doi:10.1175/2009JAS3150.1, 2010.

Muhlbauer, A., Ackerman, T. P., Comstock, J. M., Diskin, G. S., Evans, S. M., Lawson, R. P., and Marchand, R. T.: Impact of large-scale dynamics on the microphysical properties of midlatitude cirrus, J. Geophys. Res.-Atmos., 119, 3976-3996, doi:10.1002/2013JD020035, 2014.

Sassen, K.: Cirrus Clouds: A modern perspective, in: Cirrus, Oxford University Press, Inc., 11-40, 2002.

Schiller, C., Krämer, M., Afchine, A., Spelten, N., and Sitnikov, N.: Ice water content of Arctic, midlatitude, and tropical cirrus, J. Geophys. Res.-Atmos., 113, D24208, doi:10.1029/2008JD010342, 2008.

Spichtinger, P. and Gierens, K. M.: Modelling of cirrus clouds Part 1a: Model description and validation, Atmos. Chem. Phys., 9, 685-706, doi:10.5194/acp-9-685-2009, 2009a.

Spichtinger, P. and Gierens, K. M.: Modelling of cirrus clouds - Part 1b: Structuring cirrus clouds by dynamics, Atmos. Chem. Phys., 9, 707-719, doi:10.5194/acp-9-707-2009, 2009b.

Stephens, G. L., Tsay, S.-C., Stackhouse, P. W., and Flatau, P. J.: The relevance of the microphysical and radiative properties of cirrus clouds to climate and climatic feedback, J. Atmos. Sci., 47, 1742-1754, doi:10.1175/15200469(1990)047<1742:TROTMA>2.0.CO;2, 1990.

Voigt, C., Schumann, U., Minikin, A., Abdelmonem, A., Afchine, A., Borrmann, S., Boettcher, M., Buchholz, B. Bugliaro, L., Costa, A., Curtius, J., Dollner, M., Dörnbrack, A., Dreiling, V., Ebert, V., Ehrlich, A., Fix, A., Forster, L., Frank, F., Fütterer, D., Giez, A., Graf, K., Grooß, J. U., Groß, S., Heinold, B., Hüneke, T., Järvinen, E., Jurkat, T., Kaufmann, S., Kenntner, M., Klingebiel, M., Klimach, T., Kohl, R., Krämer, M., Krisna, T. C., Luebke, A., Mayer, B., Mertes, S., Molleker, S., Petzold, A., Pfeilsticker, K., Port, M., Rapp, M., Reutter, P., Rolf, C., Rose, D., Sauer, D., Schläfer, A., Schlage, R., Schnaiter, M., Schneider, J., Spelten, N., Spichtinger, P., Stock, P., Weigel, R., Weinzerl, B., Wendisch, M., Werner, F., Wernli, H., Wirth, M., Zahn, A., Ziereis, H., and Zöger, M.: MLCIRRUS - The airborne experiment on natural cirrus and contrail cirrus with the high-altitude long-range research aircraft HALO, B. Am. Meteorol. Soc., submitted, 2016.

Zhang, Y., Macke, A., and Albers, F.: Effect of crystal size spectrum and crystal shape on stratiform cirrus radiative forcing, Atmos. Res., 52, 59-75, doi:10.1016/S0169-8095(99)00026-5, 1999. 